\title{
Preparation of High Modulus Poly(Ethylene Terephthalate): Influence of Molecular Weight, Extrusion, and Drawing Parameters
}

\author{
Jian Min Zhang, ${ }^{1}$ Qingsong Hua, ${ }^{1}$ Christopher T. Reynolds, ${ }^{2}$ Yuling Zhao, ${ }^{1}$ Zuoqiang Dai, \\ Emiliano Bilotti, ${ }^{2}$ Jie Tang, $^{1}$ and Ton Peijs ${ }^{2}$ \\ ${ }^{1}$ School of Mechanical and Electrical Engineering, Qingdao University and Power \& Energy Storage System Research Center, \\ No. 308 Ningxia Road, Qingdao 266071, China \\ ${ }^{2}$ School of Engineering and Materials Science and Materials Research Institute, Queen Mary University of London, \\ Mile End Road, London E1 4NS, UK
}

Correspondence should be addressed to Jie Tang; tangjie@qdu.edu.cn and Ton Peijs; t.peijs@qmul.ac.uk

Received 29 October 2016; Revised 12 December 2016; Accepted 28 December 2016; Published 26 January 2017

Academic Editor: Alessandro Pegoretti

Copyright (C) 2017 Jian Min Zhang et al. This is an open access article distributed under the Creative Commons Attribution License, which permits unrestricted use, distribution, and reproduction in any medium, provided the original work is properly cited.

\begin{abstract}
Poly(ethylene terephthalate) (PET) which is one of the most commercially important polymers, has for many years been an interesting candidate for the production of high performance fibres and tapes. In current study, we focus on investigating the effects of the various processing variables on the mechanical properties of PET produced by a distinctive process of melt spinning and uniaxial two-stage solid-state drawing (SSD). These processing variables include screw rotation speed during extrusion, fibre take-up speed, molecular weight, draw-ratio, and drawing temperature. As-spun PET production using a single-screw extrusion process was first optimized to induce an optimal polymer microstructure for subsequent drawing processes. It was found that less crystallization which occurred during this process would lead to better drawability, higher draw-ratio, and mechanical properties in the subsequent SSD process. Then the effect of drawing temperature (DT) in uniaxial two-stage SSD process was studied to understand how DT ( $<T_{g}$ or close to $T_{g}$ or close to $T_{\text {rec }}$ ) would affect the crystallization, draw-ratio, and final mechanical properties of PET. The designed process in current work is simulated to an industrial production process for PET fibres; therefore, results and analysis in this paper have significant importance for industrial production.
\end{abstract}

\section{Introduction}

There are a number of technical routes to improve the mechanical properties of polymeric materials. The most popular method to improve the intrinsic properties of polymers is to fully align the polymer chains in the loading (e.g., fibre or film) direction in order to utilize the intrinsic stiffness and strength of polymer molecules to the maximum. Poly(ethylene terephthalate) (PET), which is one of the most commercially important polymers, has for many years been an interesting candidate for the production of high performance fibres and tapes. It was reported that $60 \%$ of the world polyester production in 2010 was consumed in the form of fibres [1]. Various methods have been investigated by previous researchers, involving spinning, drawing, and annealing processes [1-8]. These methods, including vibrating hot drawing, zone-drawing, cold-drawing, horizontal isothermal bath, draw by using high pressure $\mathrm{CO}_{2}$, and high speed in-line drawing, are quite different from each other; however, the fundamentals are the same. During these processes reorganization of amorphous and crystalline phases in the PET microstructure occurs, and it is widely accepted that orientation in both the amorphous phase and the crystalline phase is essential to achieve high mechanical properties for these fibres. It was proposed in literature $[9,10]$ that the orientating process will transform initial microstructure into a fibrillar one, which is a good way of explaining how various properties are affected by orientation.

In the traditional fibre and textile industry, there are basically two different approaches to generate chain extension 
and orientation in melt-spun or solution-spun fibres [11]: (1) applying a drawdown to the fibres during or immediately after extrusion or spinning; (2) uniaxial solid-state drawing (SSD) process of as-spun fibres at temperatures below the melting or dissolution temperature. Since relaxation processes limit the effectiveness of the induced orientation during melt spinning, uniaxial SSD process is generally considered to be more effective in achieving high degrees of orientation than the first method. Moreover, the simplicity of the SSD process can also lead to relatively low cost fibres [12]. In the 1970s, extensive studies concerning the drawability of linear polyethylene (PE) in the solid state were carried out by Ward and coworkers $[13,14]$. They developed a technological route for optimized melt spinning and subsequent SSD of linear PE, resulting in PE fibres with Young's moduli of up to $75 \mathrm{GPa}$ and tensile strengths of up to $1.5 \mathrm{GPa}$. Meanwhile, studies on the postdrawing of melt-spun polypropylene (PP) fibre have been carried out by Peijs and coworkers [15-17]; the effect of processing conditions on the mechanical properties and thermal stabilities of oriented PP fibre and/or tape was investigated in order to obtain optimal reinforcements for so-called "all-PP" or "self-reinforced PP" composites [15]. As PET has potentially much better mechanical and thermal properties than PP, the development of "all-PET" composites is of great interest. In order to achieve high performance composites, high strength and high stiffness PET reinforcements are required. Although a considerable number of studies on various spinning or drawing processes for high performance PET fibres were carried out, most studies investigated only few processing variables in just one experimental process (either spinning or drawing); little attention has been directed to in-depth investigation on the mechanism behind the influence of processing parameters on the drawability and mechanical properties of PET fibres by a continuous semi-industrial process of melt spinning and drawing.

In current work, a distinctive process of melt spinning followed by two-stage uniaxial SSD process is proposed. Theoretically, during this continuous process, polymer molecules are partially aligned by extensional flow followed by crystallization and SSD to further orient polymer chains and crystallites and to lock in molecular orientation in order to produce polymeric fibres with high mechanical properties. Here we intend to fill the knowledge gap by investigating and discussing effects of various processing variables on the drawability and mechanical properties of PET produced by this designed process. First, we investigated the optimization of as-spun PET production using a single-screw extrusion process, with the aim to induce an optimal polymer microstructure for subsequent drawing processes. Here, the effect of molecular weight, screw rotation speed, and takeup speed on the mechanical properties and crystallinity of as-spun PET was investigated. Secondly, the study focused on the optimization of the SSD process to produce high performance PET from these as-spun samples. Here, the effect of drawing temperature and draw-ratio on mechanical properties and crystallinity of PET is examined and discussed.

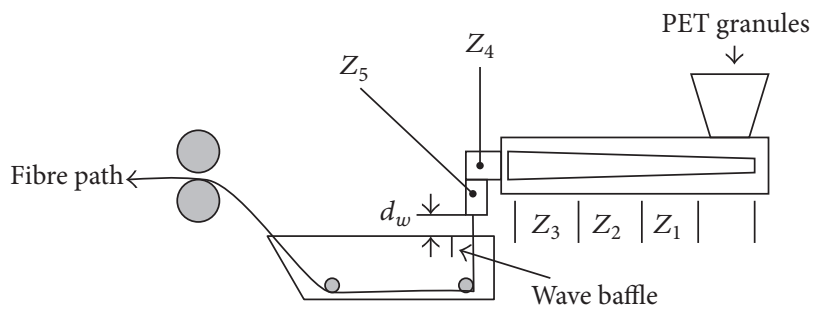

FIGURE 1: Schematic of single-screw extrusion line for preparation of as-spun precursor PET monofilaments.

TABLE 1: Extrusion parameters for PET “grade M.”

\begin{tabular}{lc}
\hline Process parameter & Value \\
\hline Zone 1 (feed zone) & $290^{\circ} \mathrm{C}$ \\
Zone 2 (compression zone) & $260^{\circ} \mathrm{C}$ \\
Zone 3 (metering zone) & $260^{\circ} \mathrm{C}$ \\
Zone 4 (vertical adaptor) & $265^{\circ} \mathrm{C}$ \\
Zone 5 (die) & $260^{\circ} \mathrm{C}$ \\
Screw rotation speed & $20 / 50 \mathrm{rpm}$ \\
Take-up speed & $10 / 20 \mathrm{~m} \cdot \mathrm{min}^{-1}$ \\
\hline
\end{tabular}

\section{Materials and Methods}

2.1. Materials. Three different grades, kindly provided by Sabic Innovative Plastics (Netherlands), were used for the preparation of PET samples. These PET grades are different in molecular weight, which is indicated by their intrinsic viscosity $([\eta])$. Because of high melt viscosity, effective melt spinning is limited to PET with $[\eta] \leq 0.8-0.9 \mathrm{dl} / \mathrm{g}$ [20]. Therefore, PET grades used in this paper were selected within this range. In this paper, from this point onwards, PET with $[\eta]=0.8$ is referred to as "grade $\mathrm{H}$," $[\eta]=0.7$ as "grade $\mathrm{M}$," and $[\eta]=0.62$ as "grade $L$," as reference to their relative high, medium, and low molecular weights.

PET is more hygroscopic than most other polymers with moisture uptake leading to hydrolysis of polymer molecules during polymer processing at high temperatures, affecting ultimate mechanical properties. Hence, PET granules were dried at $120^{\circ} \mathrm{C}$ in a conventional oven for $24 \mathrm{hrs}$ before extrusion, resulting in a residual moisture content as assessed by thermal gravimetric analysis (TGA) of $0.003 \mathrm{wt} . \%$, which is within the prerequisite limit of $<0.005 \mathrm{wt} . \%$ [21].

2.2. Optimization of Extrusion Process. Extrusion was applied to produce as-spun PET bristles for subsequent two-stage SSD process. A single-screw extrusion line (Dr. Collin Teachline ${ }^{\circledR}$ E20T) was used in this process. This extrusion line is shown schematically in Figure 1. PET granules were fed from a hopper into a laboratory single-screw extruder with a diameter of $20 \mathrm{~mm}$ and an $L / D$ ratio of 25 .

The extruder consists of five heating zones located from hopper to die, functions of which are indicated in Table 1. Temperature and pressure sensors are located in Zone 3, where melt temperature and melt pressure are measured instantaneously. Screw rotation speed was chosen to ensure a 
TABLE 2: Equipment settings for two-stage SSD process.

\begin{tabular}{lllcrrr}
\hline & Speed@S1 & T@S1 & T@S2 & Speed@S3 & T@S3 & $\lambda$ \\
\hline 1st draw & $1 \mathrm{~m} \cdot \mathrm{min}^{-1}$ & $52^{\circ} \mathrm{C}$ & $52 / 70^{\circ} \mathrm{C}$ & $5.7 \mathrm{~m} \cdot \mathrm{min}^{-1}$ & $25^{\circ} \mathrm{C}$ & 5.7 \\
2nd draw & $1 \mathrm{~m} \cdot \mathrm{min}^{-1}$ & $52^{\circ} \mathrm{C}$ & $150^{\circ} \mathrm{C}$ & $1.7 \mathrm{~m} \cdot \mathrm{min}^{-1}$ & $25^{\circ} \mathrm{C}$ & 1.7 \\
\hline
\end{tabular}
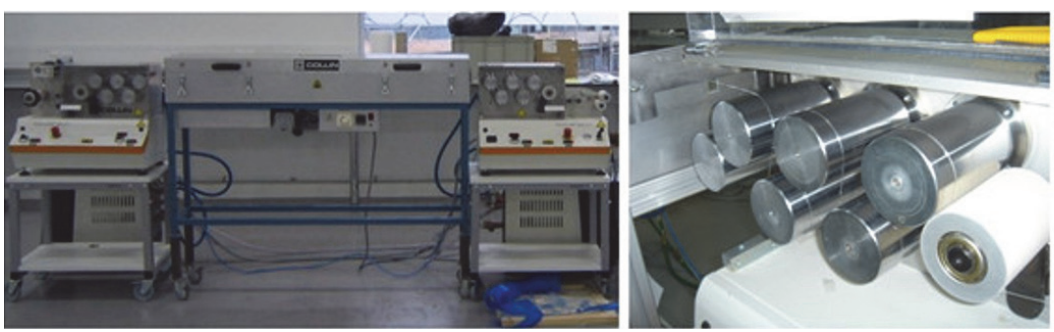

(a)

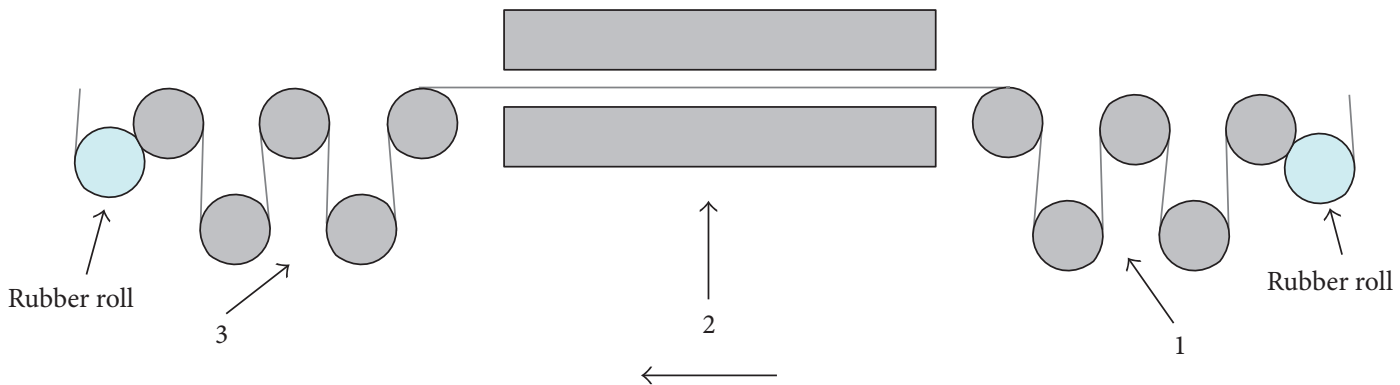

Fiber drawing direction

(b)

Figure 2: (a) Photographs of the monofilament drawing line, from left to right: complete drawing line; close view of holding back godet rolls (Section 1); and close view of take-off godet rolls (Section 3); (b) schematic of monofilament drawing line: Section 1, temperature controlled holding back godets; Section 2, hot air oven; Section 3, temperature controlled take-off godets plus winder.

moderate residence time of the melt in the extruder. The melt was extruded through a die orifice with a diameter of $1 \mathrm{~mm}$ into a quenching water bath. The distance between die head and water bath surface $\left(d_{w}\right)$ was set at $5 \mathrm{~mm}$ to avoid melt drawdown and ensure a stable process. Next, the extruded monofilament was wound up on a cold roller which was set to $0^{\circ} \mathrm{C}$ at a take-up speed which was chosen to ensure a stable process. These as-spun bristles would be precursors for a subsequent solid-state drawing process to achieve high modulus and tensile strength.

The temperature settings of the five heating zones, the screw speeds, and take-up speeds for PET grade $\mathrm{M}([\eta]=$ $0.7 \mathrm{dl} / \mathrm{g}$ ) are shown in Table 1 . A relatively high temperature is needed in Zone 1 to achieve a constant polymer feed, but this cannot exceed $300^{\circ} \mathrm{C}$ to avoid polymer degradation [22]. Screw rotation speeds of $20 \mathrm{rpm}$ and $50 \mathrm{rpm}$ and takeup speeds of $10 \mathrm{~m} \cdot \mathrm{min}^{-1}$ and $20 \mathrm{~m} \cdot \mathrm{min}^{-1}$ were selected to investigate their effects on as-spun PET crystallinity.

Melt pressure became stable after $30 \mathrm{~min}$ in operation; therefore only as-spun samples spun after this time period were considered for subsequent SSD process.

2.3. Optimization of Solid-State Drawing (SSD) Process. A distinctively designed SSD process of melt-extruded bristles was used to create highly oriented PET. After extrusion and take-up, as-spun PET samples proceeded to Dr Collin Teachline Mono-axial Stretching Units MDO-AT and MDOBT (Germany). Here the monofilament was drawn in two discrete stages: in the first stage, the sample was drawn at temperatures close to $T_{g}$ to a draw-ratio $\lambda_{1}=5.7$, while, in the second stage, a further draw-ratio, $\lambda_{2}=1.7$ was applied by drawing the sample through an oven at $150^{\circ} \mathrm{C}$. The product of the first draw-ratio, $\lambda_{1}$ and the second draw-ratio, $\lambda_{2}$ gave the total draw-ratio of $\lambda=9.7$.

$$
\lambda=\lambda_{1} \times \lambda_{2}
$$

Every drawing stage consisted of three sections, which are shown in Figure 2. Section 1 (S1) is a temperature controlled holding back godets (MDO-AT) unit with a rubber roll at the beginning. Section 2 (S2) is a hot air tunnel oven, with an air blower at one end near S3; air flow was adjustable through an operating panel. Section 3 (S3) is temperature controlled take-off godets (MDO-BT) with a winding station.

The equipment settings in the first and second drawing stage are listed in Table 2.

During the first drawing stage, the hot air oven temperature was set to $52^{\circ} \mathrm{C}$ and $70^{\circ} \mathrm{C}$, respectively. Therefore, the 


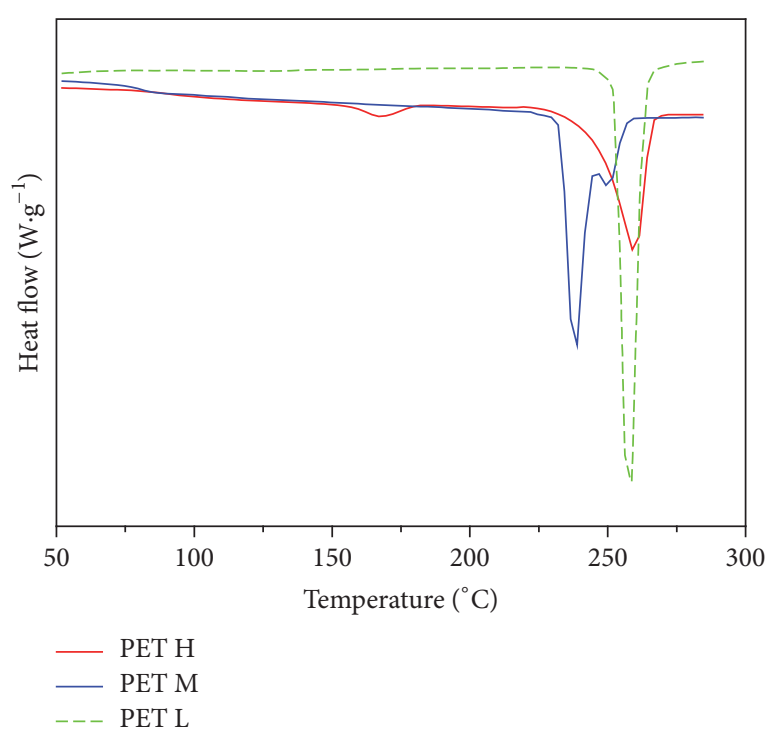

(a)

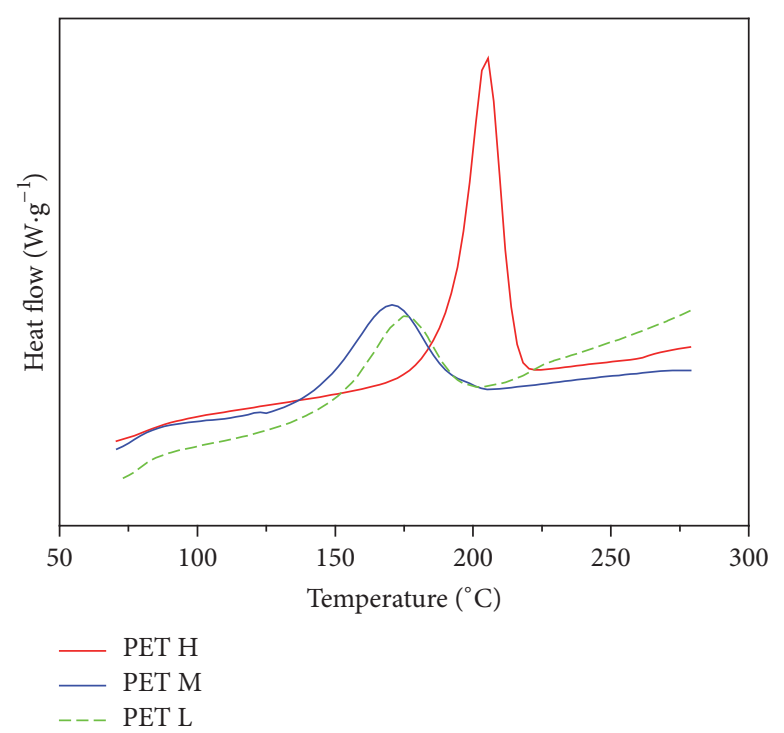

(b)

FIGURE 3: DSC traces of different PET grades: (a) heating trace; (b) cooling trace, indicating melting and crystallization behaviour of PET grades $\mathrm{L}, \mathrm{M}$, and $\mathrm{H}$.

effect of drawing temperature on the mechanical properties of PET was investigated. Furthermore, crystallinity and mechanical properties of PET after 1st and 2nd drawing stages were compared to investigate its effect on maximum drawratio.

\subsection{Characterization}

2.4.1. Differential Scanning Calorimetry (DSC). DSC measurements were performed to determine the melting temperature of the different PET grades and to determine the degree of crystallinity of as-spun and drawn PET samples, using a Mettler-Toledo 823e (Germany), at a constant heating and cooling rate of $10^{\circ} \mathrm{C} \cdot \mathrm{min}^{-1}$. The data obtained records the crystalline melting temperature, which is shown as an endothermal peak. The degree of crystallinity was determined by (2), assuming a linear relationship between endothermal peak area and crystallinity. Heat of fusion was calculated by the integration of the endothermal peak area in the evaluated temperature range.

$$
C=\frac{\Delta H}{\Delta H_{0}} \times 100 \%,
$$

where $C$ is crystallinity of semicrystalline polymer, $\Delta H$ is heat of fusion of semicrystalline polymer, and $\Delta H_{0}$ is heat of fusion of $100 \%$ crystalline material (for PET, this is taken as $140.1[\mathrm{~J} / \mathrm{g}][23])$.

2.4.2. Tensile Testing. Tensile tests of monofilaments was performed using an Instron tensile testing machine 5566 equipped with a $1 \mathrm{kN}$ load cell, special force reducing fibre grips, and Bluehill data acquisition software. A gauge length of $200 \mathrm{~mm}$ and a cross-head displacement of $20 \mathrm{~mm} \cdot \mathrm{min}^{-1}$ were used. Strength was defined here as the maximum stress recorded in tension, while strain to failure was defined as the strain at which the load is reduced by $70 \%$. Young's modulus was determined in the strain range of $0.1-0.5 \%$. The monofilament diameter was measured by a digital Vernier Caliper at five different locations along the sample, and an average value was then calculated.

\section{Results and Discussion}

3.1. Effect of Molecular Weight on Draw-Ratio. In this study, grades $\mathrm{H}, \mathrm{M}$, and $\mathrm{L}$ are named indicating PET of comparatively high, medium, and low molecular weight. Figure 3 shows the DSC heating and cooling traces of PET grades L, M, and $\mathrm{H}$. The endothermic melting peaks with melting ending temperature of $268^{\circ} \mathrm{C}$ for grade $\mathrm{H}, 256^{\circ} \mathrm{C}$ for grade $\mathrm{M}$, and $266^{\circ} \mathrm{C}$ for grade $\mathrm{L}$ are used to determine the extrusion barrel zone temperature settings for these different PET grades, while the exothermic crystallization peaks during cooling are indicative of the crystallization temperature $\left(200^{\circ} \mathrm{C}\right.$ for grade $\mathrm{H}, 170^{\circ} \mathrm{C}$ for grade $\mathrm{M}$, and $175^{\circ} \mathrm{C}$ for grade $\mathrm{L}$, respectively), degree of supercooling, and degree of crystallinity in the asspun PET samples.

It was recently reported by La Mantia et al. [24-26] that the key factors for achieving and maintaining orientation in extrusion process are the intensity of elongational flow, relaxation times, and cooling rate. The elongational flow induces the orientation of polymer molecules along the flow direction [26]. During extrusion, polymers with lower intrinsic viscosity $[\eta]$ (grade $\mathrm{L}$ in this case) will have faster elongational flow which helps orientate polymer molecules. However, the length of oriented chains is limited by low viscosity (i.e., low molecular weight). In order to retain the orientation, higher relaxation time of polymer melt and crystallization during cooling is desirable [26]. By comparing the endothermic melting peaks in DSC heating traces for 
three kinds of PET grades, it is found that the widths of melting peaks are different for grades $\mathrm{H}\left(\sim 40^{\circ} \mathrm{C}\right), \mathrm{M}\left(\sim 30^{\circ} \mathrm{C}\right)$, and $\mathrm{L}\left(18^{\circ} \mathrm{C}\right)$. The DSC tests are performed under a constant heating and cooling rate of $10^{\circ} \mathrm{C} \cdot \mathrm{min}^{-1}$; therefore, it indicates that grade $\mathrm{H}$ has the longest relaxation time during melting. Although the melting conditions in the actual extrusion process are different with the conditions in DSC tests, we can still analyse the relative differences for three PET grades with the purpose of a qualitative comparison. The cooling rate in the extrusion process is much higher than that of DSC tests, but the crystallization behaviour indicated from DSC cooling traces can still be compared for three PET grades in order to give some insights for real extrusion process. By integrating the areas under exothermic crystallization peaks, it is found that grades $\mathrm{M}$ and $\mathrm{L}$ are easier to crystallize than grade $\mathrm{H}$, which indicates that the induced orientation is easier to be "frozen" by crystallization for grades $\mathrm{M}$ and $\mathrm{L}$.

During melt extrusion chain orientation and extension is often limited due to fast relaxation processes in the polymer melt where entropic forces cause chains to return back to their random coil conformation. However, it is well known that polymer chains can be efficiently oriented below their melting temperature, that is, in the solid state where relaxation times are infinite. Provided the temperature is sufficiently low to avoid chain relaxation, the induced polymer orientation and hence fibre stiffness increase with increasing draw-ratio [27]. Seminal work by Ward and coworkers [28] showed that Young's modulus of a fibre typically increases linearly with draw-ratio. Moreover, they also showed that the maximum attainable draw-ratio strongly depends on weight average molar mass $\left(M_{w}\right)$ of the polymer [28].

The maximum attainable draw-ratio of a polymer depends on its molecular weight as follows [27]:

$$
\lambda_{\max }=\left(\frac{l_{p}}{l}\right)\left(\frac{n}{C_{\infty}}\right)^{1 / 2},
$$

where $n$ is the number of chain segments having a length $l$ and a projected length $l_{p}$ in the chain direction and $C_{\infty}$ is the characteristic chain stiffness. It is understood from (3) that long and perfectly oriented macromolecules are needed to obtain high draw-ratio. However, increasing molecular weight typically results also in a reduction of both spinnability and drawability in the solid state as a result of increased entanglement density [29]. In terms of spinnability, a strong increase in molecular weight will cause problems related to die-swell and difficulties in producing homogeneous filaments [29]. As for drawability, chains in extruded and solidified filaments of very high molecular weight become more difficult to extend because of the high entanglement density, limiting the maximum attainable draw-ratio that can be achieved [12]. Hence, a balance is needed between high molecular weight for tensile strength and medium or low molecular weight for drawability, chain orientation/extension, and Young's modulus.

It was observed that at drawing temperatures far below their melting temperatures the maximum attainable drawratio of as-spun PET bristles which were produced from grade $\mathrm{M}$ was significantly higher than for samples produced

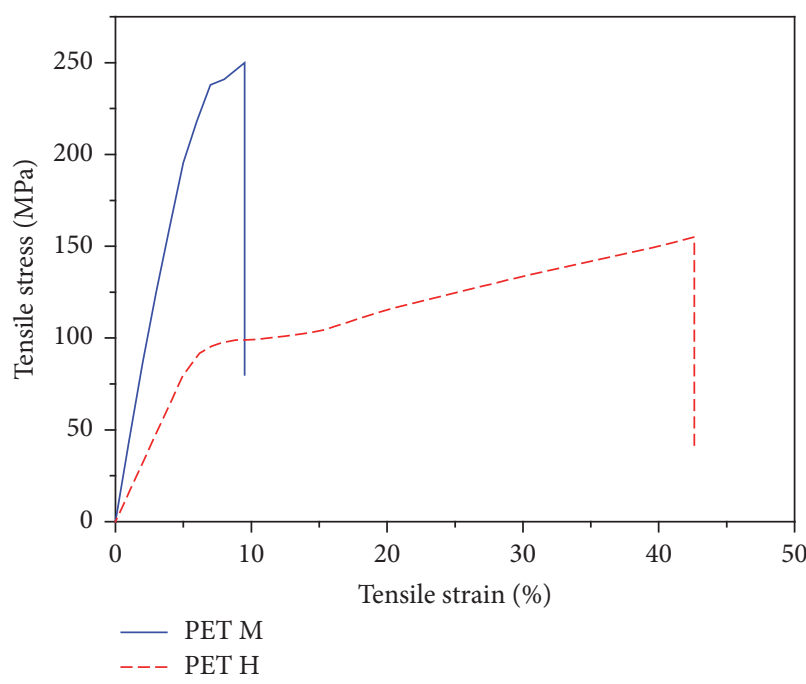

FIGURE 4: Tensile behaviour of as-spun PET bristles produced from grades $\mathrm{H}$ and $\mathrm{M}$, indicating a higher Young's modulus and ultimate tensile strength for samples produced from grade $\mathrm{M}$.

from grades $\mathrm{H}$ and $\mathrm{L}$. Meanwhile, Young's modulus of as-spun bristle from grade $\mathrm{H}$ is much lower than that from grade $\mathrm{M}$ (Figure 4).

Balanced from the above results by a comprehensive analysis, PET grade $\mathrm{M}$ with medium molecular weight was chosen as the raw material for the precursor; meanwhile, only grade $\mathrm{M}$ is used in the following section and discussion.

3.2. Effect of Screw Rotation Speed and Take-Up Speed. The crystallinity of as-spun PET bristles extruded at different screw rotation speeds is listed in Table 3, indicating a crystallinity of $4.5 \%$ for a screw speed of $20 \mathrm{rpm}$ and a crystallinity of $6.9 \%$ for $50 \mathrm{rpm}$ (after subtracting the crystallinity at the recrystallization peak from the crystallinity at the melt peak). The take-up speed for the as-spun bristles was $10 \mathrm{~m} \cdot \mathrm{min}^{-1}$. Higher screw rotation speed induces higher intensity of elongational flow. As mentioned earlier, elongational flow will help to orientate polymer molecules in the melt [26]. Furthermore, during rapid cooling process after extrusion, more crystallites will be formed in these oriented regions. High crystallinity in as-spun bristles is disadvantageous for subsequent SSD processes because crystalline regions acts as physical cross-links preventing chain extension. In order to create an optimal polymer morphology for achieving high draw-ratios by SSD, $20 \mathrm{rpm}$ was chosen here for the extrusion process.

The crystallinity of as-spun PET bristles extruded at $20 \mathrm{rpm}$ and different take-up speeds are listed in Table 4 . Crystallinity of as-spun PET bristles was calculated at $4.5 \%$ and $3.0 \%$ for take-up speeds of $10 \mathrm{~m} \cdot \mathrm{min}^{-1}$ and $20 \mathrm{~m} \cdot \mathrm{min}^{-1}$, respectively. Although polymer molecules tend to orient more at higher drawdown or take-up speeds, insufficient crystallization at higher take-up speeds may result in a lower degree of crystallinity. As mentioned earlier, low crystallinity in precursor samples is preferred for achieving higher drawratios in subsequent drawing processes. Therefore, a take-up 
TABLE 3: Crystallinity of as-spun PET bristles extruded at different screw rotation speeds at a take-up speed of $10 \mathrm{~m} \cdot \mathrm{min}^{-1}$.

\begin{tabular}{lcc}
\hline & \multicolumn{2}{c}{ Crystallinity } \\
& $\begin{array}{c}\text { @Screw rotation speed } \\
20 \mathrm{rpm}\end{array}$ & $50 \mathrm{rpm}$ \\
\hline (1) @ Recrystallization peak & $24.9 \%$ & $24.1 \%$ \\
$(2) @$ Melt peak & $29.4 \%$ & $31.0 \%$ \\
$(2)-(1)$ & $4.5 \%$ & $6.9 \%$ \\
\hline
\end{tabular}

TABle 4: Crystallinity of as-spun PET bristles extruded at $20 \mathrm{rpm}$ and different take-up speeds.

\begin{tabular}{lcc}
\hline & \multicolumn{2}{c}{$\begin{array}{c}\text { Crystallinity } \\
\text { @Take-up speed }\end{array}$} \\
& $10 \mathrm{~m} \cdot \mathrm{min}^{-1}$ & $20 \mathrm{~m} \cdot \mathrm{min}^{-1}$ \\
\hline (1) @ Recrystallization peak & $24.9 \%$ & $25.6 \%$ \\
$(2) @$ Melt peak & $29.4 \%$ & $28.6 \%$ \\
$(2)-(1)$ & $4.5 \%$ & $3.0 \%$ \\
\hline
\end{tabular}

speed of $20 \mathrm{~m} \cdot \mathrm{min}^{-1}$, leading to the lowest degree of crystallinity, was here chosen for the extrusion process.

\subsection{Effect of Draw-Ratio}

3.3.1. Mechanical Properties of Solid-State Drawn PET. Young's moduli and tensile strengths of drawn samples after the first drawing stage $\left(\mathrm{T} @ \mathrm{~S} 2=52^{\circ} \mathrm{C}\right)(\lambda=5.7)$ and second drawing stage $(\lambda=9.7)$ are shown in Figure 5.

Draw-ratios applied at each drawing stage were the maximum achievable draw-ratios for a stable running of the monofilament drawing line. The maximum final draw-ratio of the PET is $\lambda=9.7$, which results in a maximum Young's modulus of $16 \mathrm{GPa}$ and a tensile strength of $925 \mathrm{MPa}$. Young's modulus is strongly controlled by orientation of amorphous regions, which have a function of load transfer between crystalline lamellae. Tie molecules in amorphous regions can become taut during the drawing process enabling efficient load transfer between crystals. As expected an increase of tensile modulus is seen with increasing draw-ratio. Clearly two-stage drawing results in better ultimate mechanical properties than single-stage drawing only. According to the network structure concept [19], these improved properties are attributed partly to the reduction in network shrinkage during drawing and partly due to a possible modification of the network during the second drawing stage. It was also pointed out by De Clerck et al. [30] that a heatsetting process (between $T_{g}$ and $T_{m}$ ) can be regarded as a very short annealing treatment during which some melting and recrystallization will occur for the least stable crystals as well as some crystallization of the amorphous regions. Therefore, it can be explained that during the second drawing stage not only were more polymer chains oriented but also recrystallization occurred to further improve the mechanical properties of drawn PET. Figure 6 shows the decreasing trend in strain at break of PET after each drawing stage, indicating

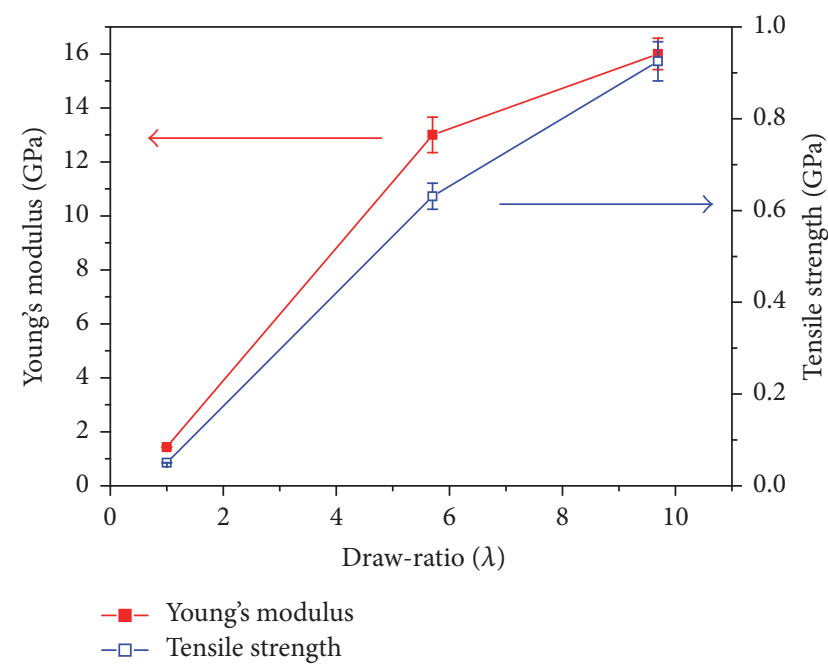

FIGURE 5: Mechanical properties of as-spun PET bristle $(\lambda=1)$, solid-state drawn PET after the first draw $(\lambda=5.7)$, and second draw $(\lambda=9.7)$, respectively.

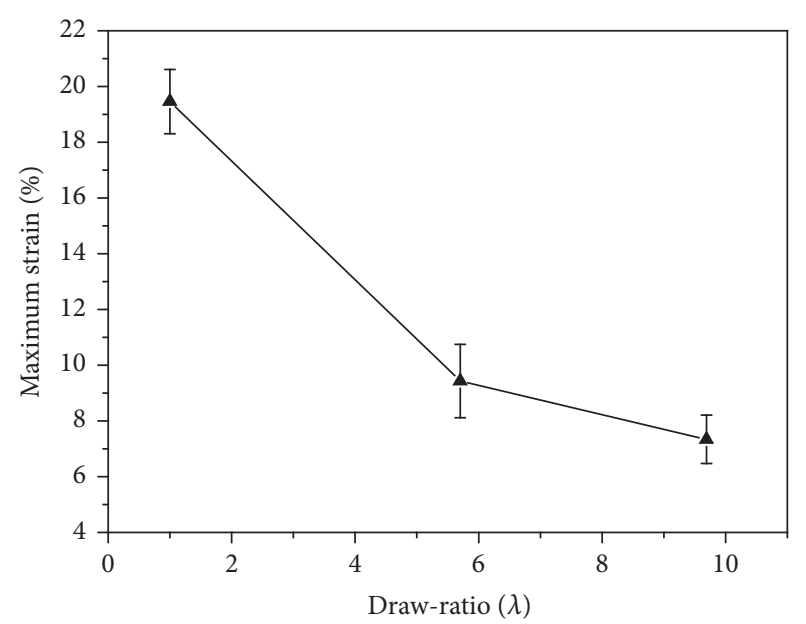

FIGURE 6: Strain to failure of as-spun PET bristle $(\lambda=1)$, solid-state drawn PET after the first draw $(\lambda=5.7)$, and second draw $(\lambda=9.7)$, respectively.

further that molecular extension is more restrained in samples of higher draw-ratio.

3.3.2. Model Prediction of PET Modulus. In above tensile test results, Young's modulus was calculated assuming Hookean behaviour in the elastic regime of the stress-strain curve. However, it is well known that Young's modulus of fibres increases with increasing gauge length [31]. This is because in the calculation of Young's modulus, the compliance of the equipment in which fibres are tested is not taken into account. With increasing gauge length, the influence of the testing equipment will decrease. Therefore only Young's moduli obtained from longer gauge length samples are expected to approach the real intrinsic modulus value. As the intrinsic Young's modulus is only measurable for samples of infinitely large gauge length, it can instead be obtained by extrapolation 
from a series of measured Young's moduli at varying gauge lengths. Here, the intrinsic Young's modulus of PET $(\lambda=$ 9.7) was obtained from tensile tests at different gauge lengths $(100 \mathrm{~mm}, 200 \mathrm{~mm}$, and $300 \mathrm{~mm})$, with data extrapolation indicating a real Young's modulus value for the PET of 20.2 GPa (Figure 7).

Young's moduli after the first and second drawing stage are in good agreement with the Irvine-Smith model, which predicts that Young's modulus uniquely depends on the applied draw-ratio $(\lambda)$ according to the following [27]:

$$
\begin{aligned}
E & =\left(E_{u}^{-1}-\left[\frac{3 \lambda^{3}}{2\left(\lambda^{3}-1\right)}[1\right.\right. \\
& \left.\left.-\left(\lambda^{3}-1\right)^{-1 / 2} \tan ^{-1}\left\{\left(\lambda^{3}-1\right)^{1 / 2}\right\}\right]-\frac{1}{2}\right]\left(E_{u}^{-1}\right. \\
& \left.\left.-E_{h}^{-1}\right)\right)^{-1} .
\end{aligned}
$$

For $\lambda \geq 5$ this expression reduces to a good approximation by:

$$
E=\left[E_{h}^{-1}+\left(E_{u}^{-1}-E_{h}^{-1}\right)\left(\frac{3 \pi}{4}\right) \lambda^{-3 / 2}\right]^{-1},
$$

where $E_{h}$ and $E_{u}$ are the respective tensile moduli of the perfectly oriented and nonoriented polymer. From the above equations, the axial tensile modulus $E$ is a unique function of the draw-ratio $\lambda$. In the case of oriented PET, $E_{h}=108 \mathrm{GPa}$ [32], $E_{u}=2.8 \mathrm{GPa}, \lambda=5.7$, and 9.7, respectively. From this the predicted axial tensile modulus $E=14.4 \mathrm{GPa}$ for $\lambda=5.7$ and $E=27.4 \mathrm{GPa}$ for $\lambda=9.7$. These model predictions compare well to reasonably well with experimental data of $E=13 \mathrm{GPa}$ (@ $\lambda=5.7$ ) and $E=20.2 \mathrm{GPa}$ (@ $\lambda=9.7$ ), indicating that the tensile modulus of oriented PET is in excellent agreement with theoretical predictions after the first drawing stage, while the model slightly overestimates the modulus after the second drawing stage. During the first drawing, a large amount of oriented crystallites are created, which become a hindrance for further tensile drawing in stage two. Hence, the tensile modulus after the second drawing stage is slightly lower than predicted since such effects are ignored in the model [27]. This phenomena was also already seen in Figure 5 where it was shown that the modulus developed less than linear after the first drawing stage.

3.3.3. Crystallinity of Drawn PET. During the designed SSD process, there was a noticeable change in appearance of the samples. As-spun samples appeared transparent. However, already after the first drawing stage PET started to become opaque, indicating the formation of microfibrils and voidrich structures similar to phenomena reported in the drawing of PP fibre/tape [15].

DSC heating curves of the as-spun PET bristles after fibre extrusion are plotted in Figure 8, indicating a $T_{g} \approx 75^{\circ} \mathrm{C}$ and crystallinity of $3 \%$ in this precursor.

Figure 9 compares the crystallinity of drawn samples after the first and second drawing stages. The degree of crystallinity

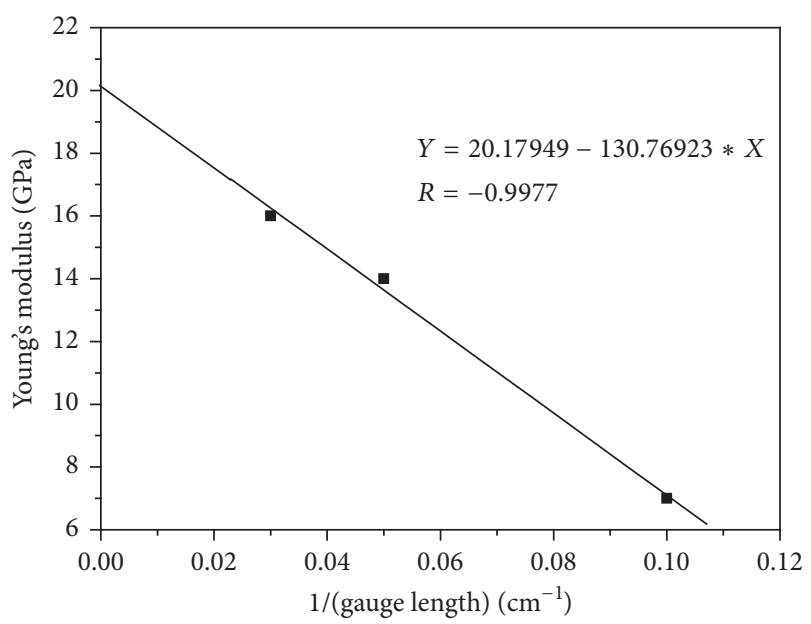

FIgURE 7: Extrapolation of the Young's modulus as a function of gauge length to estimate the true Young's modulus for solid-state drawn PET after the 2nd drawing $(\lambda=9.7)$.

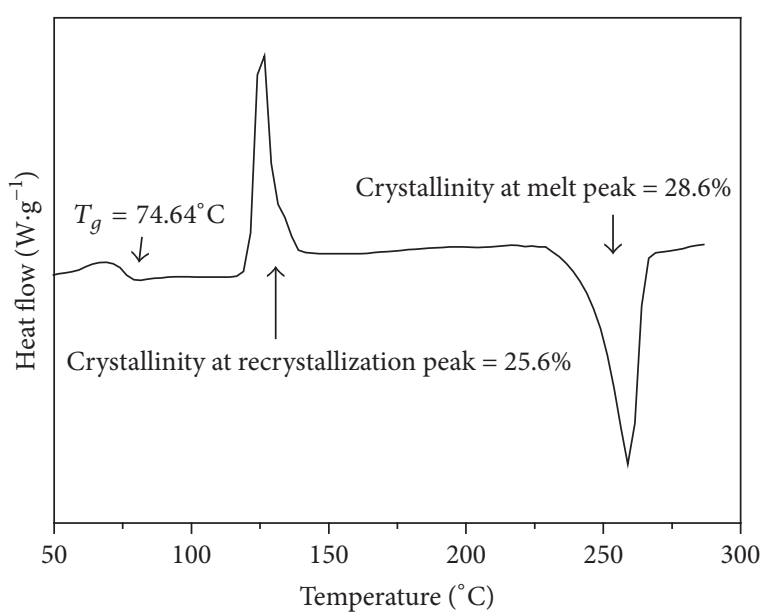

FIGURE 8: DSC heating trace of as-spun PET bristle, indicating $T_{g} \approx$ $75^{\circ} \mathrm{C}$ and a recrystallization temperature at around $125^{\circ} \mathrm{C}$.

of drawn PET increases by over 30\% after the two-stage drawing process. However, after the second drawing stage, the degree of crystallinity of PET increased by as little as $1 \%$ compared to samples after the first drawing stage. A larger increase in crystallinity was expected after the second drawing step since recrystallization of the polymer may occur in this second drawing step [30]. As indicated by De Clerck et al., prolonged cold crystallization at $100^{\circ} \mathrm{C}$ for bulk amorphous PET leads to a reduction of the amount of amorphous phase, hence an increase in crystallinity; meanwhile, higher annealing temperatures (e.g., $130^{\circ} \mathrm{C}-150^{\circ} \mathrm{C}$ ) for only $2 \mathrm{~min}$ resulted in the onset of recrystallization.

3.4. Effect of Drawing Temperature. PET samples were drawn in the first stage in a hot air oven (S2) at $52^{\circ} \mathrm{C}$ and $70^{\circ} \mathrm{C}$, respectively. Figure 10 shows the effect of drawing temperature on the mechanical properties of PET after the first drawing stage. 
TABLE 5: A comparison of mechanical properties of PET produced in this work and in literature.

\begin{tabular}{|c|c|c|c|c|c|}
\hline & This work & Kunugi et al. [18] & Fakirov and Evstatiev [2] & Long and Ward [19] & Suzuki et al. [5] \\
\hline $\begin{array}{l}\text { Draw-ratio } \\
(-)\end{array}$ & 9.7 & - & 20 & - & - \\
\hline $\begin{array}{l}\text { Tensile modulus } \\
\text { (GPa) }\end{array}$ & 20.0 & 19.4 & 18.6 & 17.5 & 15.1 \\
\hline $\begin{array}{l}\text { Tensile strength } \\
\text { (GPa) }\end{array}$ & 0.93 & 0.80 & 0.6 & 0.97 & 1.20 \\
\hline $\begin{array}{l}\text { Strain to failure } \\
\text { (\%) }\end{array}$ & 7.3 & 5.9 & 16 & - & 7.0 \\
\hline
\end{tabular}

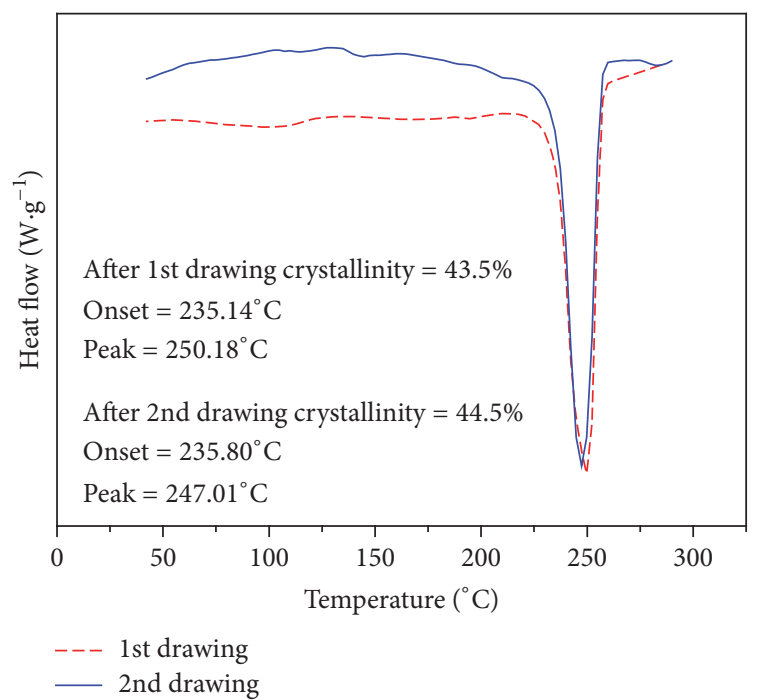

FIGURE 9: DSC heating traces of solid-state drawn PET, showing the degree of crystallinity after the first and second drawing stages.

Due to relaxation of tie molecules in amorphous regions at temperatures closer to $T_{g}$, Young's modulus decreases and strains to failure increases with drawing temperature. The effect of drawing temperature on network orientation has been studied in detail by Blundell et al. [33]. It was pointed out in their work that higher drawing temperatures lead to an increase in mobility of the main chain, enabling oriented chains to retract through entanglements, while slow drawing rates increase the opportunity for chains to retract within the same timescale as the development of orientation [33]. Although a drawing temperature of $70^{\circ} \mathrm{C}$ is rather modest compared to temperatures used in literature $\left(\sim 80^{\circ} \mathrm{C}\right)[19,34]$, the drawing speed used in our study of $5.7 \mathrm{~m} \cdot \mathrm{min}^{-1}$ was too low to prevent retraction of extended chains in the network. Hence, increasing the drawing temperature to a temperature closer to $T_{g}$ while not offset by an increased drawing speed may lead to relaxation of tie molecules in amorphous regions and a reduction of Young's modulus. Tensile strength of PET after the first drawing stage also decreased with increasing drawing temperature as shown in Figure 10.

A comparison of mechanical properties of PET achieved in this work and some data from literature is given in

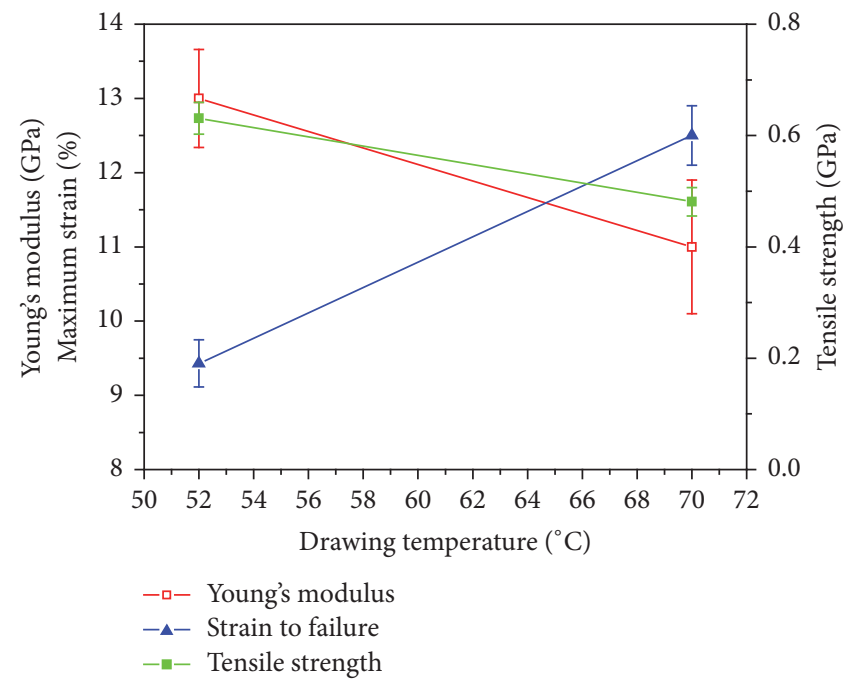

FIGURE 10: The effect of drawing temperature on mechanical properties of PET after the first drawing stage.

Table 5, showing a comparably high performance, especially high modulus of PET by this continuous process. Unlike other studies, the current work investigated a continuous spinning and drawing process which was simulated to an industrial production process for PET fibres and discussed all processing variables during this process; therefore, results and analysis in this paper have significant importance for industrial production.

\section{Conclusions}

A distinctive continuous process of extrusion followed by two-stage SSD process was exploited to produce high modulus PET. The effects of polymer molecular weight and various processing parameters on the mechanical properties and crystallinity of PET were investigated and discussed in this paper. The polymer grade used for the final production of the PET monofilaments was chosen concerning the effect of molecular weight on polymer drawability. High draw-ratios are necessary to achieve high levels of molecular orientation and therefore high Young's modulus, while high molecular weights are preferred for high tensile strength. The extrusion 
conditions of as-spun PET determine the morphology of the precursors for the subsequent drawing process, including the level of preorientation and crystallinity. It is shown that crystallization in as-spun PET bristles should be avoided in order to achieve higher draw-ratios and high levels of molecular orientation in subsequent drawing processes. Drawing conditions in the solid state of PET clearly affect the mechanical properties and thermal stability of the resulting materials. Young's modulus and tensile strength of PET were both improved by higher draw-ratios. Drawing temperatures approaching $T_{g}$ led to a reduction in Young's modulus as a result of relaxation of tie molecules in amorphous regions. Recrystallization during second-stage drawing led to further improvement in mechanical properties of the final PET samples. It was also shown that the tensile modulus of drawn PET after single-stage drawing was in excellent agreement with predicted moduli according to the Irvine-Smith model. However, the Young's modulus after the second drawing stage was slightly lower than model predictions due to the development of crystallites during drawing. A comparison of mechanical properties of PET achieved in this work and some literature data indicated comparably high mechanical performance, especially high modulus of the PET samples obtained by this continuous process. The designed process in current work was simulated to an industrial production process for PET fibres; therefore, results and analysis in this paper have significant importance for industrial production.

\section{Competing Interests}

The authors declare that they have no competing interests.

\section{Acknowledgments}

The authors would like to thank Sabic Innovative Plastics (former GE Plastics) (Netherlands) for providing raw materials. The melt extrusion, uniaxial SSD process, and tensile tests were conducted in Nanoforce Technology Ltd (UK) and DSC measurements were performed in open lab in SEMS, QMUL. Authors from Qingdao University would like to thank Shandong Taishan Scholar Program for financial support.

\section{References}

[1] H. Avci, M. Najafi, A. Kilic, and R. Kotek, "Highly crystalline and oriented high-strength poly(ethylene terephthalate) fibers by using low molecular weight polymer," Journal of Applied Polymer Science, vol. 132, no. 45, 2015.

[2] S. Fakirov and M. Evstatiev, "New routes to polyethylene terephthalate with improved mechanical properties," Polymer, vol. 31, no. 3, pp. 431-434, 1990.

[3] T. Kunugi and A. Suzuki, "Preparation of high-modulus poly(ethylene terephthalate) fibers by vibrating hot drawing," Journal of Applied Polymer Science, vol. 62, no. 4, pp. 713-719, 1996.

[4] T. Hobbs and A. J. Lesser, "Preparation of high performance poly(ethylene terephthalate) fibers: two-stage drawing using high pressure $\mathrm{CO}_{2}$," Polymer, vol. 41, no. 16, pp. 6223-6230, 2000.

[5] A. Suzuki, K. Toda, and T. Kunugi, "Application of a cycle zonedrawing/zone-annealing method to poly(ethylene terephthalate) fibers," Polymer, vol. 41, no. 16, pp. 6061-6066, 2000.

[6] W.-G. Hahm, H. Ito, and T. Kikutani, "Analysis of necking deformation behavior in high-speed in-line drawing process of PET by on-line diameter and velocity measurements," International Polymer Processing, vol. 21, no. 5, pp. 536-543, 2006.

[7] T. Yamaguchi, K. Kim, T. Murata et al., "Initial stage of fiber structure development in the continuous drawing of poly(ethylene terephthalate)," Journal of Polymer Science, Part B: Polymer Physics, vol. 46, no. 19, pp. 2126-2142, 2008.

[8] A. Haji, R. S. Rahbar, and B. Kalantari, "The effect of hot multistage drawing on molecular structure and optical properties of polyethylene terephthalate fibers," Materials Research, vol. 15, no. 4, pp. 554-560, 2012.

[9] A. Peterlin, "Drawing and extrusion of semi-crystalline polymers," Colloid \& Polymer Science, vol. 265, no. 5, pp. 357-382, 1987.

[10] D. C. Prevorsek, Y. D. Kwon, and R. K. Sharma, "Structure and properties of Nylon 6 and PET fibres: the effects of crystallite dimensions," Journal of Materials Science, vol. 12, no. 11, pp. 2310-2328, 1977.

[11] C. W. M. Bastiaansen, "High-modulus and high strength fibers based on flexible macromolecules," in Materials Science and Technology: A Comprehensive Treatment, R. W. Cahn, P. Haasen, and E. J. Kramer, Eds., pp. 552-577, VCH, Cambridge, Mass, USA, 1997.

[12] T. Peijs, M. J. N. Jacobs, and P. J. Lemstra, "High performance polyethylene fibers," in Comprehensive Composite Materials, A. Kelly and C. Zweben, Eds., vol. 1 of Fiber Reinforcements and General Theory of Composites, pp. 263-301, Elsevier, Amsterdam, The Netherlands, 2000.

[13] G. Capaccio, A. G. Gibson, and I. M. Ward, Ultra-High Modulus Polymers, Elsevier Applied Science, London, UK, 1979.

[14] G. Capaccio and I. M. Ward, "Properties of ultrahigh modulus linear polyethylenes," Nature Physical Science, vol. 243, no. 130, p. 143, 1973.

[15] B. Alcock, N. O. Cabrera, N. M. Barkoula, and T. Peijs, “The effect of processing conditions on the mechanical properties and thermal stability of highly oriented PP tapes," European Polymer Journal, vol. 45, no. 10, pp. 2878-2894, 2009.

[16] T. Schimanski, J. Loos, T. Peijs, B. Alcock, and P. J. Lemstra, "On the overdrawing of melt-spun isotactic polypropylene tapes," Journal of Applied Polymer Science, vol. 103, no. 5, pp. 2920-2931, 2007.

[17] T. Schimanski, T. Peijs, P. J. Lemstra, and J. Loos, "Influence of postdrawing temperature on mechanical properties of meltspun isotactic polypropylene," Macromolecules, vol. 37, no. 5, pp. 1810-1815, 2004.

[18] T. Kunugi, A. Suzuki, and M. Hashimoto, "Preparation of high-modulus and high-strength poly(ethylene terephthalate) fiber by zone annealing," Journal of Applied Polymer Science, vol. 26, no. 1, pp. 213-221, 1981.

[19] S. D. Long and I. M. Ward, "Tensile drawing behaviour of polyethylene terephthalate," Journal of Applied Polymer Science, vol. 42, no. 7, pp. 1911-1920, 1991.

[20] A. Ziabicki, "Effects of molecular weight on melt spinning and mechanical properties of high-performance poly(ethylene terephthalate) fibers," Textile Research Journal, vol. 66, no. 11, pp. 705-712, 1996. 
[21] J. M. Chopinez and J. F. Briois, "Method for processing polyethylene terephthlate," International Patent WO/2016/005493, 2016.

[22] G. Chen, J. A. Cuculo, and P. A. Tucker, "Effects of spinning conditions on morphology and properties of polyethylene terephthalate fibers spun at high speeds," Journal of Applied Polymer Science, vol. 44, no. 3, pp. 447-458, 1992.

[23] B. Wunderlich, "Equilibrium melting of flexible linear macromolecules," Polymer Engineering \& Science, vol. 18, no. 6, pp. 431-436, 1978.

[24] F. P. La Mantia, R. Arrigo, and M. Morreale, "Effect of the orientation and rheological behaviour of biodegradable polymer nanocomposites," European Polymer Journal, vol. 54, no. 1, pp. 11-17, 2014.

[25] F. P. La Mantia, M. C. Mistretta, R. Scaffaro, L. Botta, and M. Ceraulo, "Processing and characterization of highly oriented fibres of biodegradable nanocomposites," Composites Part B: Engineering, vol. 78, pp. 1-7, 2015.

[26] F. P. La Mantia, M. Ceraulo, M. C. Mistretta, and M. Morreale, "Effect of hot drawing on the mechanical properties of biodegradable fibers," Journal of Polymers and the Environment, vol. 24, no. 1, pp. 56-63, 2016.

[27] P. A. Irvine and P. Smith, "Development of the axial young's modulus with draw ratio of flexible-chain polymers," Macromolecules, vol. 19, no. 1, pp. 240-242, 1986.

[28] I. Ward, P. Coates, and M. Dumoulin, Solid Phase Processing of Polymers, Carl Hanser Verlag GmbH \& Co. KG, 2000.

[29] P. Smith, R. R. Matheson Jr., and P. A. Irvine, "Extension ratios of polymer molecules," Polymer communications Guildford, vol. 25, no. 10, pp. 294-297, 1984.

[30] K. De Clerck, H. Rahier, B. Van Mele, and P. Kiekens, “Thermal properties relevant to the processing of PET fibers," Journal of Applied Polymer Science, vol. 89, no. 14, pp. 3840-3849, 2003.

[31] L. C. Pardini and L. G. B. Manhani, "Influence of the testing gage length on the strength, young's modulus and weibull modulus of carbon fibres and glass fibres," Materials Research, vol. 5, no. 4, pp. 411-420, 2002.

[32] K. Nakamae, T. Nishino, and Y. Gotoh, “Temperature dependence of the elastic modulus of the crystalline regions of poly(ethylene 2,6-naphthalate)," Polymer, vol. 36, no. 7, pp. 14011405, 1995.

[33] D. J. Blundell, A. Mahendrasingam, C. Martin et al., "Orientation prior to crystallisation during drawing of poly(ethylene terephthalate)," Polymer, vol. 41, no. 21, pp. 7793-7802, 2000.

[34] B. Huang, M. Ito, and T. Kanamoto, "Effects of draw conditions on deformability and draw efficiency of high molecular weight poly(ethylene terephthalate) fibres," Polymer, vol. 35, no. 6, pp. 1329-1331, 1994. 

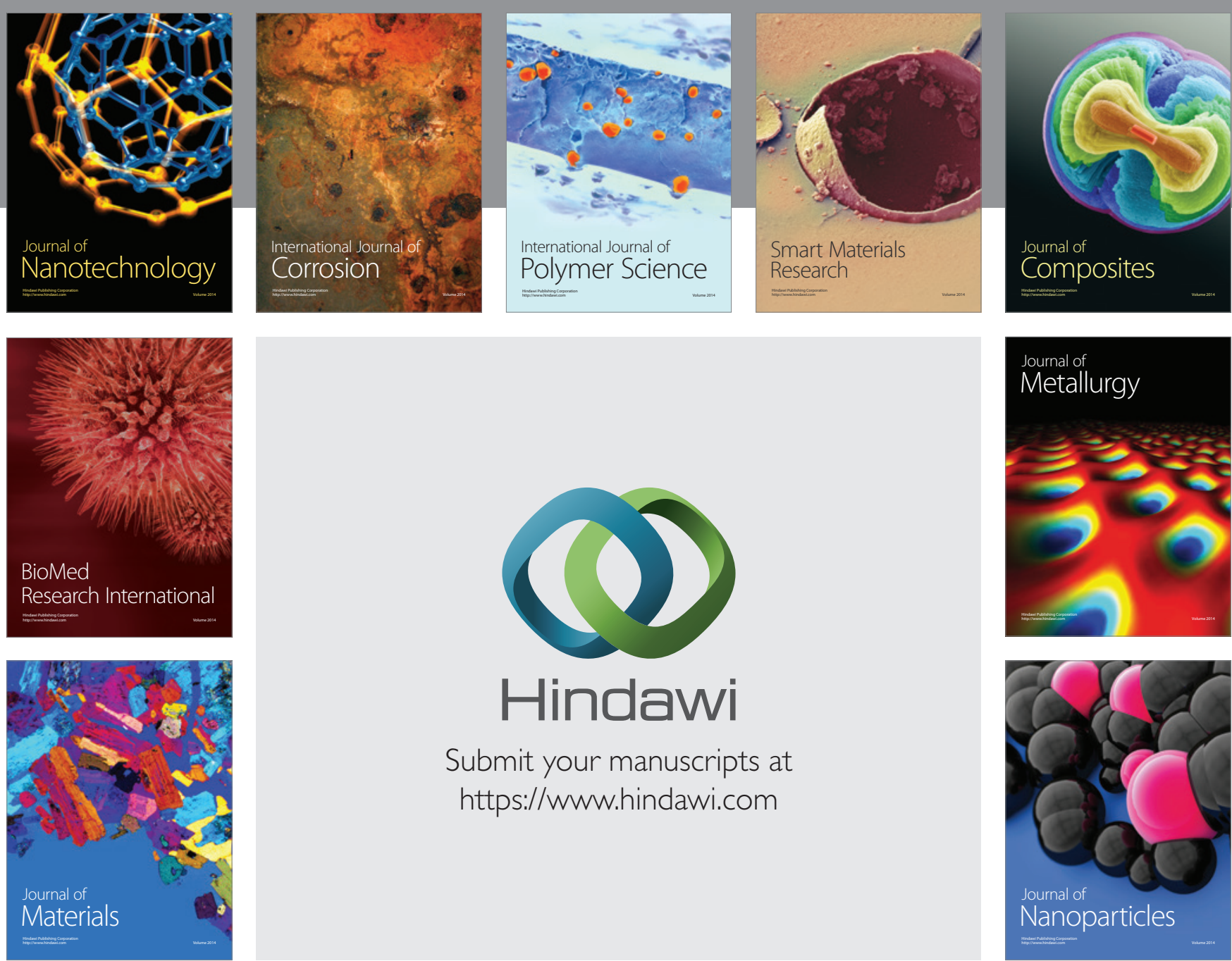

\section{Hindawi}

Submit your manuscripts at

https://www.hindawi.com

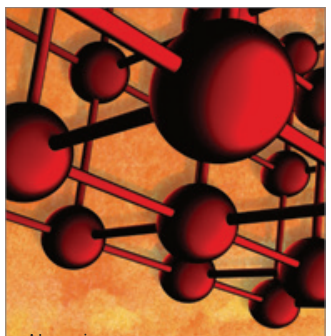

Materials Science and Engineering
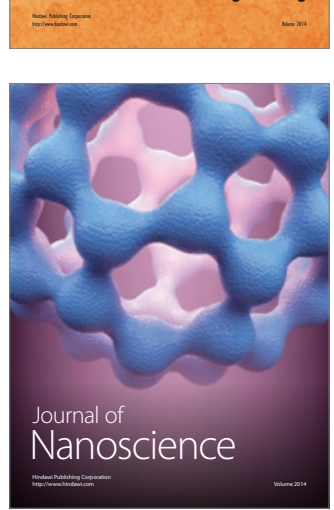
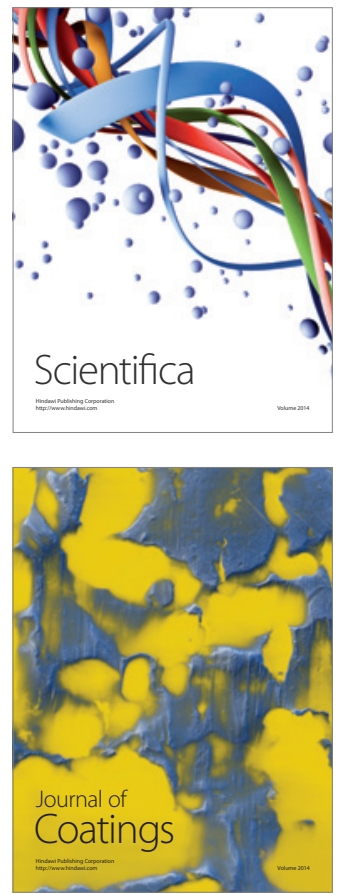
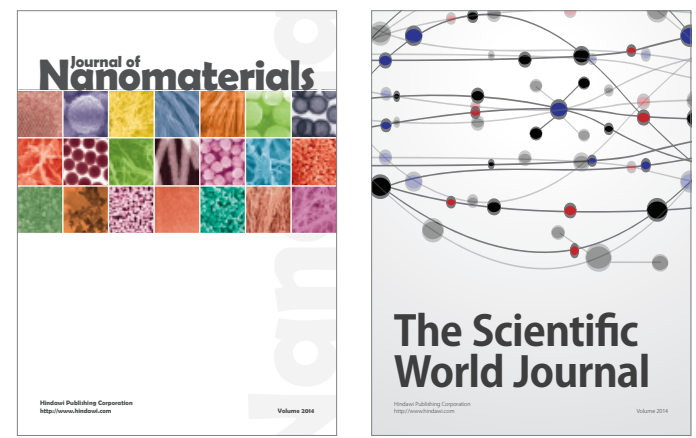

The Scientific World Journal
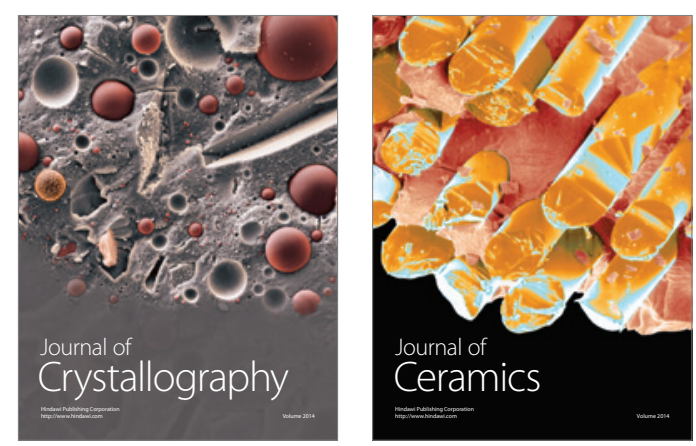
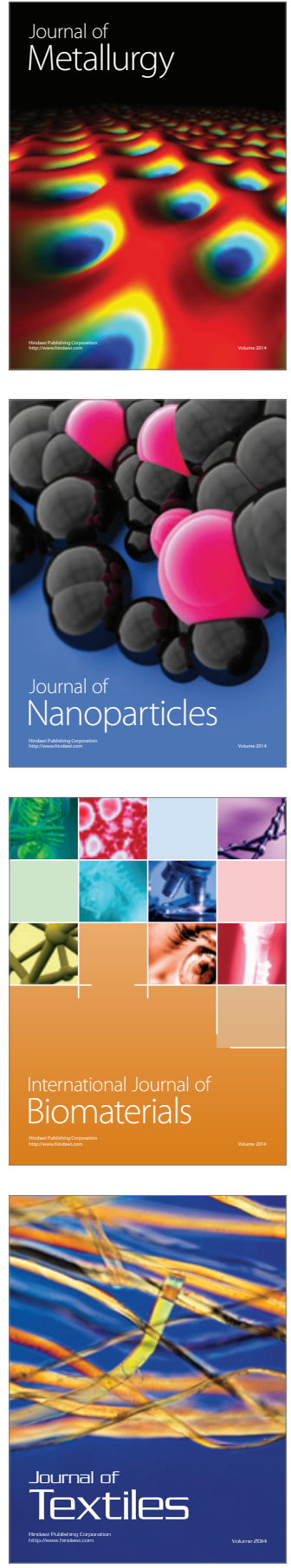